Indo Global Journal of Pharmaceutical Sciences, 2018; 8(1): 26-32

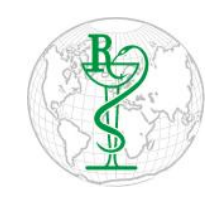

INDO GLOBAL JOURNAL OF

PHARMACEUTICAL SCIENCES

ISSN 2249- 1023

\title{
Thirty Six Year Old Platinum as an Anticancer Agent
}

\author{
Priyank Purohit ${ }^{1 *}$, Satyender Kumar ${ }^{1}$, Vikram Sharma ${ }^{1}$, Madulika Singh ${ }^{2}$ \\ ${ }^{I}$ Department of Pharmacy, School of Medical and Allied Sciences, Galgotias University, Gautam Buddh Nagar, Greater Noida, Uttar Pradesh \\ 201310, India \\ ${ }^{2}$ Sai Life Sciences, Rajiv Gandhi Infotech Park, Hinjewadi Phase-2, Pune
}

\begin{abstract}
Address for
Correspondance

Priyank Purohit,

priyank.purohit@

galgotiasuniversit

y.edu.in ;

priyank.niper@g

$\underline{\text { mail.com }}$

Received:

28.11.2017

Accepted:

11.02.2018

ABSTRACT: The cancer treatment has been a challenge since it was diagnosed first. In that stage the primary focus centre of medicinal chemist was to combat a serious problem. So far many drugs have been approved for the cancer treatment, however, the side effects and resistance set them in corner. In pursuit of better drug candidate the first metal coordinating drug cisplatin came up with a wide range of anticancer activity. Metal coordinating drugs having anticancer activity open a new era of metal coordinating drugs. Efforts for the fine tuning of platinum coordinating anticancer compound leads to better option like carboplatin and oxaloplatin, however their resistance and some severe side effects made their limited use. The platinum drug has been modified in many ways to improve the safety profile as well the activity, moreover many derivatives were approved by the agencies. The endless efforts with the limited success turn the discovery to the different direction; in the recent scenario the existing drugs were modified to better pharmacokinetic parameters. The drug with improved pharamcokinetis parameter found less toxic compare to the parent drug, moreover among the modified drug some are going successfully in the clinical studies with the combination or alone. The ease of synthesis of these metal based molecules was an attraction for scientist to develop the structure activity relationship of the metal base core structure. Here in the focus is to highlight the importance of platinum in the cancer treatment with recent scenario. (C) 2018 iGlobal Research and Publishing Foundation. All rights reserved.
\end{abstract}

Keywords Anticancer; Cisplatin; Platinum; Ruthenium; Coordinating Group; Multi-Targets; Polymer; Cytotoxicity; Multi-Metal Ligands; Oxidation; Target Delivery; Clinical Studies; Pharmacokinetics.

\section{INTRODUCTION}

The organometals has been widely used as a catalyst in the organic chemistry for the synthesis of complex molecules, due to their coordinating capability. Serendipities discovery of platinum metal as a cytotoxic agent from the platinum electrode was a key opener for the era of metal based anticancer agents. The discovery of the Pt related drug cisplatin has been an attraction for inorganic as well organic chemist. The ease of synthesis of these metal coordinating compounds also made them very economical for the cancer treatment.[1] The first metal based anticancer drug cisplatin was found effective only for certain types of solid tumors. The continuous dosing of the drug was the key problem to accelerate the side effect as well the resistance to the cancer cell, however, the drug resistant and some side effects lead the discovery to the second generation of drug. The newer generation drug approach to the target was found with the newer way, compare to the cisplatin. The resistance and side effect lead to the metal to the next generation of the drug. [2]

\section{Classical Platinum coordinating anticancer drug}

The accidental discovery of metal based cisplatin by the Rosenberg was a classical discovery in the field of medicinal chemistry. This discovery opened a use of organic metals not in organic synthesis but in the drug discovery science. The serendipitous discovery was based on the platinum 


\section{Indo Global Journal of Pharmaceutical Sciences, 2018; 8(1): 26-32}

electrode.[1] The mode of action was not clear in the earlier stage but later, it was found that cisplatin forms adduct with the DNA and causes cell death. The detail mechanistic study found that the influx of neutral cisplatin inside the cell causes activation of the cisplatin by the replacement of one of the chloro legend to the aqua ligand (water molecule) as depicted in figure 1, which converts neutral species to the cationic species. The aqua species is a electrophile species, which binds with the nucleophoilic centre of the neucleotide. The study found that the activation require the cis geometry of the molecules. The activated cisplatin interact with the N7 position of Guinine, which cause the disturbance in the cell programmed and cause cell apoptosis.

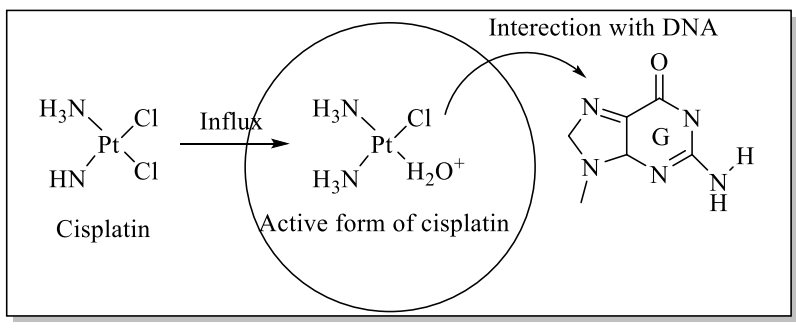

Figure 1- Activation of cisplatin

The major drawback of the drug resistance, which highlighted after the successful passed by the various drug agencies. The drug resistance was mainly due to the limited influx of drug inside the cell. The detail study based on the resistance found many factor for the resistance. The study related to the resistance found that thiol substance (glutathione) alters the effect of cisplatin to the cancer cell. Due to the less diffusibility of cisplatin inside the cell it requires transporters and in the case of resistance the transportation get resistance which decrease the amount of drug inside the cell. Further detail study of cisplatin resistance explains the various reasons among them the DNA repairing effects. Clearly indicated that the reason for resistance in the cancer cell by the continuous dosing, which interferes with the drug absorption. [3]

The drawback like drug resistance and nephrotoxicity and the narrow spectrum of the cisplatin lead to the other platinum based drug, where the leaving group of metal was replaced with dicarboxylate ligand and other group, moreover the many essential feature was replaced and tried to get the better drug candidate as depicted in figure 1.

\section{Non classical Platinum coordinating anticancer drug}

Carboplatin a first derivative of cisplatin, was found less toxic for the normal cell, this was later approved by FDA. The safety related data also makes the drug beneficial. [4] The mechanism of action of carboplatin was found similar but the improved pharmacokinetic profile made the drug safer as well as wider in the scope for the treatment of solid tumors. (Figure 2)[5] As per as the resistance is concern the corboplatin found effective in the initial study for cancer resistance cell, but in the later stage the result found inferior. The reason of resistance was found similar as cisplatin. The molecular mechanistic based on the molecule and the cell based study found the scope for further derivatization of the platinum metal for the betterment of the drug profile.[6]

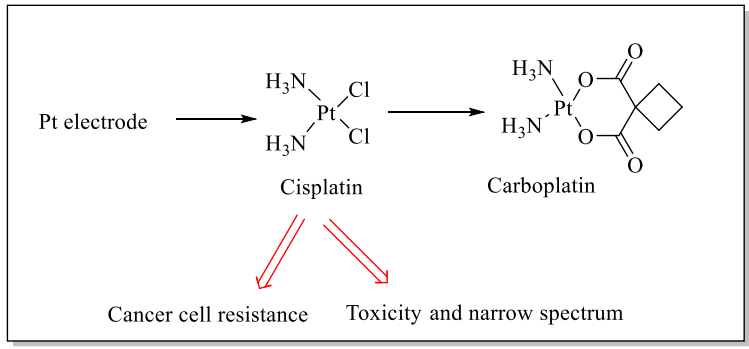

Figure 2- Journey of carbopaltin

A metal based study revealed that the as number of metal increased the metal exert beneficially effect in the pharamacophore. it was viewed that the effect of metal was increased when the multi-metallic system was used, however, the mechanism of cell death was found different. The multi metal centralized drug showed beneficial cytotoxicty effect compare to monometalic system. This study headed toward many lead molecules in newer generation of the platinum based drug as depicted in figure 3 [7].

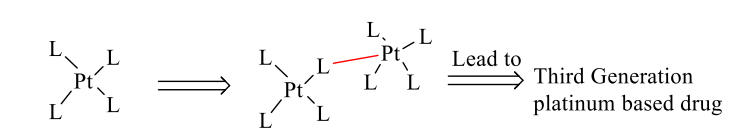

Figure 3- Demonstration of multi metal based to the third generation drug.

The problem of resistance with the cisplatin and carboplatin lead to the search of the further improved version of cisplatin derivatives. The diamine was replaced with cyclohexandiamine in the metal based anticancer agent for cisplatin resistance cancer cell as well to search for improved scope. The oxaliplatin came in to picture with effective against many solid tumors cells, [8]. It was found form the analysis of different study that the oxaliplatin is somewhat better than previous platinum based drug for certain resistance cancer cell. [9] The clinical study further explored the combination therapy of oxaliplatin-5-flurouracil- leucovorin, in the cancer cell. The result of these combination drug therapy found that these combination drugs are superior to clinical candidate for the certain type of cancer cell. [10] The ongoing research based on the mechanistic study of anticancer drug found that cell death occurs due to the apoptosis process, which is a 


\section{Indo Global Journal of Pharmaceutical Sciences, 2018; 8(1): 26-32}

common approach for cell death. The peculiar mechanism of the cell death makes the drug good in combination or alone for resistant cancer cell. [11] Some cispatin related other platinum based anticancer was regionally approved due to their limited used of the drug. The nedaplatin was approved in Japan, heptaplatin approved in South korea and lobaplatin in china. These drugs resembles with cisplatin structurally as well related to the spectrum of activity to the cisplatin. (Figure 4).

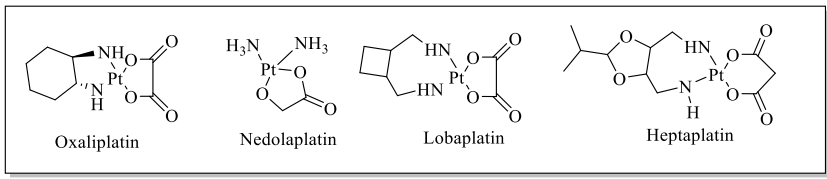

Figure 4- Closely cisplatin related drug

The structure activity relationship study of the platinum based anti cancer agent reveals some essential features for the activity. In this core metal two types of ligand generally found, the one which is for the pharmacokinetic properties known as leaving group ligand, which does not form adduct with DNA, moreover the another ligand Non-Leaving group ligands, which does not alter during the metabolism and play important role in the cytotoxicity of the metal complex. The non leaving ligand generally found with the nitrogen atom. [12]

\section{Third generation of platinum based drugs}

The resistance and the limited scope of the platinum based drug found the scope for the development of the new generation of the drug. The need of the advancement in the mode of action was necessary so that the resistance with the target would be different. The different approach for the latest generation drug has been tried among them some are using different metal ligand system as well the polymetalic ligand and different oxidation state bearing metals with good efficacy better than the classical metal based drug. The third generation of the metal has been tried to get the drug with better safety profile. The development of metal based drug is provided here with current scenario. In search of the broader spectrum as well the less toxic anti cancer drug, many efforts have been made in the past thirty years. In this report we try to cover the approach for the development of new generation of drug, the effort by the drug discovery scientist to achieve the better platinum based drug. The approach for the third generation drug is demonstrated in the figure 5. Their special character which makes them differ from other generation drug as depicted in below given figure. [13].

In early nineties the satraplatin [bisacetatoammine dichloro cyclohexylamin platinum (IV)], was developed for anticancer activity. The sataraplatin was found advantageous over other platinum based drug due to their better oral bioavailability. The oral administration of the drug is very lucrative for the metal based drug. [14] The satraplatin based study found that the drug produces similar effect to the cell as cisplatin does, which formed bond with DNA to inhibit the essential function of the cell. [15] The platinum IV inactive form of platinum gets converted to the active Pt (II) species. The prodrug phenomena causes drug to be less toxic to the normal cell. [16] Tetraplatin, and iproplatin, platinum IV derivatives were tried and showed satisfactory results for further development. [17]

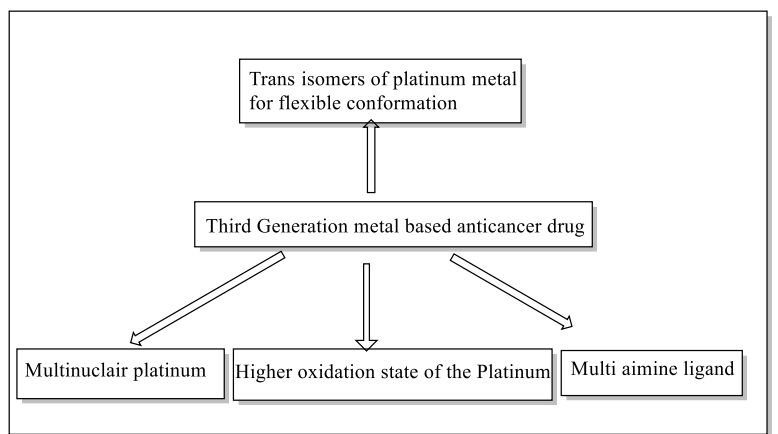

Figure 5- Different approaches for the next generation metal based drug.

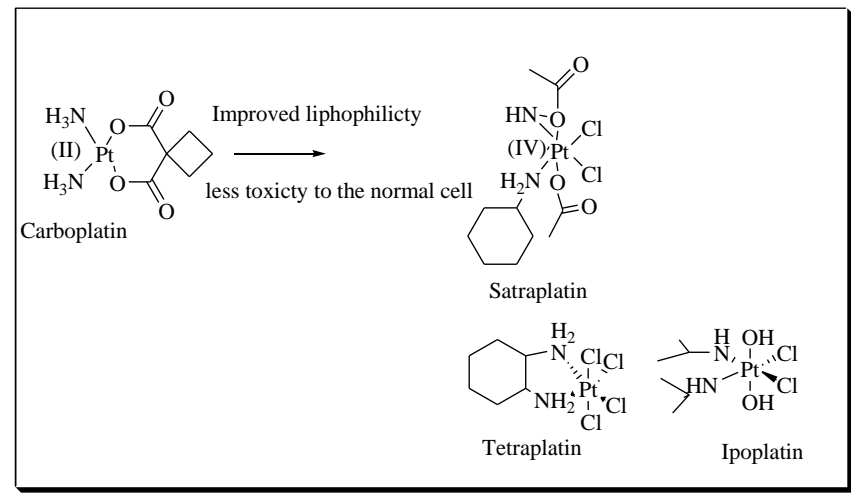

Figure 6- Chemical structure of staraplatin, tetraplatin, ipoplatin, LA-12.

The recent study based on the redox potential of the platinum drug by the near infrared study found the good reason of selectivity of cancer cell. Higher to lower oxidation of the metal inside the human body was attracted to many scientists to work on this kind of selectivity.[18] The Picoplatin [cisamminedicholoro (2-methylpyridine) platinum(II)], a stearically hindered cis derivative of cisplatin.[19], which found better for cisplatin as well oxaplatin resistant cancer cell.[20] 


\section{Indo Global Journal of Pharmaceutical Sciences, 2018; 8(1): 26-32}

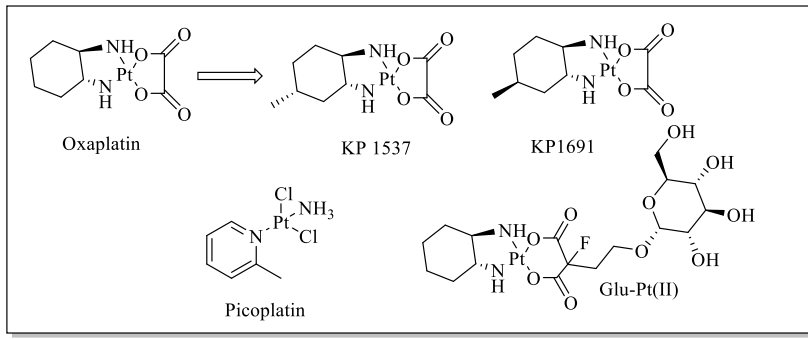

Figure 7- Chemical structure of staraplatin, picoplatin, BBR3464 and Triplatin-NC.

New derivatives of platinum based anticancer drug the picoplatin (cis-amminedichloro, 2-methylpyridine), platinum (II) and liphophilic derivatives of oxaliplatin (KP1537 and KP 1691) were developed. These derivatives found superior than the classical drug but the later clinical study revealed their certain disadvantages, which was the reasoned for not selected as a clinical candidate. In picoplatin, steric hindered ligand was used for the flexible conformation, which is responsible for stable metabolite. The BBR 3464, a multinuclear metal containing drug was found effective as well better for the platinum resistant cancer cell. [21] The drug was found synergistic with the combination of other drug in certain kind of cancer cell. [22] Recently a group found the positive effect when they added glucose as a ligand to the basis skeleton oxaplatin and tested and found better activity then parent compounds in the initial in-vitro as well in-vivo activity. [23]

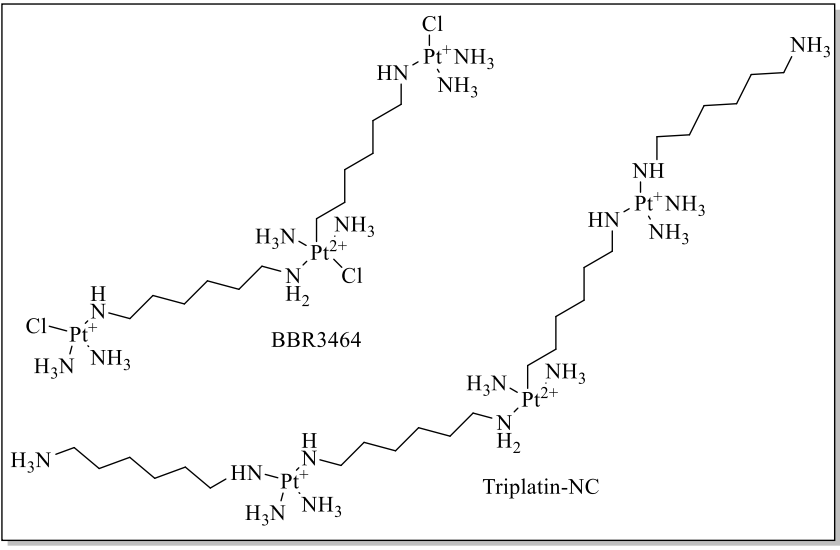

Figure 8- Chemical structure of BBR3464 and TriplatinNC.

Trinuclear metal containing drug Tripaltin-NC found with a suitable non-covalent interaction with the DNA and also exert their cytotoxic effect to the certain cancer cell. The interaction with DNA was a non classical and provided some advantages then other drug [24]. Existing platinum metal based drug showed good activity but the not much advantageous than the previous drug, which was the reason that all scientist turned discovery to the another then study moved toward the betterment of the certain pharmacokinetic parameters. The preformulation study of the existing drug to improve the bioavailability of the drug candidate and also provide the target delivery to reduce the toxicity of the drug to the other cell. The prolindac an improved oxaliplatin, which is the polymer linked drug formulation, was designed to improve the some pharmacokinetic parameter of the native drug. [25] The drug was designed for the purpose of the targeted delivery and it was observed during the clinical study of the drug that the desired formulation of the drug is a advantageous approach to get the better drug candidate, moreover the new formulated drug was found effective against different solid tumors. [26] The oxaliplatin was further formulated with the liposomal for the increase safety as well efficacy, named as Lipoxal [27], moreover, the liposomal analogous (Aroplatin ) was developed to recently to enhance the pharmacokinetic parameters [28]. In the past few years many liposomal linked drugs were introduced as a clinical candidate for the better safety profile as well the efficacy. The liposome liked cisplatin (Lipoplatin), was found better for cytotoxicity as well as wider scope [29]. Recently the modified derivative of oxilaplatn NC4016 is undergoing the clinical study and made the drug discovery open for the improved version of the formulation for the target drug delivery [30]. Past few years many efforts has been made to sharpen the drug discovery for the better metal based drug. The main aim of the modification was to improve their pharmacokinetic parameter, by using different polymers, polymer micelles and nano tubes. These efforts will progress toward the discovery to achieve the less toxic as well the better activity profile bearing candidate in a cheaper way. [31] The recent finding with the novel drug delivery system has been also incorporated in this field. The approach with the combination with other drug like histone deacytylase inhibitors was found surprising for the it's efficacy to the metal resist cell these results shows the different direction for the metal based drug development. (31a).To increase the efficiency as well the reduced toxicity to the normal cell the hybrid platinum based anticancer drug was tried through the Silica metal based drug delivery, the initial in-vitro study gave some positive direction.(31 b).

\section{Ruthenium metal based anticancer drug-}

The simultaneous discovery of the anticancer ruthenium based transition metal complexes has also emerge as a good alternate for the treatment of severe disease. Here in the brief discussion about the ruthenium metal has been covered. Ruthenium based drug converts in to active from after it absorb from the cancer cell. This phenomenon makes the ruthenium different from other metal. The metal molecule exerts their action by interacting different sites. Compare to other metal, the ruthenium metal shows low toxicity, high selectivity and high efficacy to the cancer cell. Different coordination sites and octahedral geometry provide sensitivity to ruthenium metal for 


\section{Indo Global Journal of Pharmaceutical Sciences, 2018; 8(1): 26-32}

redox reaction, which is a beneficial effect that could utilize to form the prodrug. It is well know that the prodrug could not produce any harmful effect [32]. There are many Ru based drugs are in the clinical studies, among them NAMI-A; RAPTA-T and KP1019 found promising. These compound shows anti tumor cell activity by forming new substrate. NAMI-A and KP1019 reduced to Ru (II) in tumor cells as the fast growing tumor cells causes the poor nutrient and blood supply to the cancer cell. Therefore, they can be considered as prodrugs which can gent converted to the active species.[33] The most promising kinetics by the $\mathrm{Ru}$ with their ligands and prone to oxidation state, which makes them flexible conformational for suitable binding to the naturally found molecules with the naturally accepted binding, which makes the $\mathrm{Ru}$ complex suitable for most accepted molecule for medicinal purpose. Ligand exchange to $\mathrm{Ru}$ (III) form $\mathrm{Ru}$ (II) is as Pt (II).Therefore; they are highly kinetic stable and prevent equilibration reactions. [34] The coordination environment of ruthenium plays an important role in difference oxidation state ruthenium and dictates the redox properties of central metal atom. Ruthenium exists in +2 and +3 oxidation states. Some ruthenium anticancer complexes showed potent enzyme inhibiting and DNA interaction activities. [35] In spite of the significant Pre-clinical data none of the ruthenium compounds have reached clinical testing to show their effects by these probable mechanisms. In the Phase I clinical trial of NAMI-A there was blister formation on the hands and feet. The ruthenium concentration in these blisters was below the detection limit so there may be chances that the ligand of ruthenium gets accumulated in the epidermis causing permanent or temporarily toxicity. Ruthenium compounds are second generation transition metal chemotherapies that possess unique properties. [36] In Pre-clinical studies they showed more selective entry into tumor cells with minimal toxic effect to normal cells. But yet more work is to be in the clinical studies for bringing out a positive outcome.

\section{CONCLUSION}

The journey of a metal based anticancer drug from the serendipitous development to the clinical candidate is highlighted here (especially the platinum metal) and designed in schematic presentation in figure 9 and represented as a flow chart. After the discovery of the first clinical candidate there were many successful metal based clinical candidate has been came up with the better activity in to the market in word wide as well as in the regional market. The metal based drug came up with a better option due to the ease of synthesis and the broader spectrum of activity. Eventually the drug resistance and the toxicity was found a crucial for the cancer treatment, so the scientist discover the reason for resistance and came up with new generation anticancer agents, which was producing the cytotoxic effect with different mode.

In the later stage the approach had been changed and the prodrug concept by changing the oxidation state of metal, poly metallic as well the hindered legend was trued, unfortunately these drug could not crossed the clinical stage. Various newer approaches was tried to synthesized better drug molecule but none of the approach was found suitable to get the clinical approach. The unfortunate result make the discovery toward the improvement of the existing clinical candidate by improving their pharmacokinetics parameter, by changing the polymer for the side specific study, which was found the better approach, so the drug discovery turn to improve their pharmacokinetic parameter. Different approach like the change in the career for improvement of release profile, and the target specific formulation was found impressive and many came up with a new hope in the clinical study. In the near future the improvement of result will based on their improved pharmacokinetic results as well the new approach where the bimetallic, system of the molecule will improve the drug efficacy as well the other parameter, which will be successful to make the drug a clinically successful candidate.

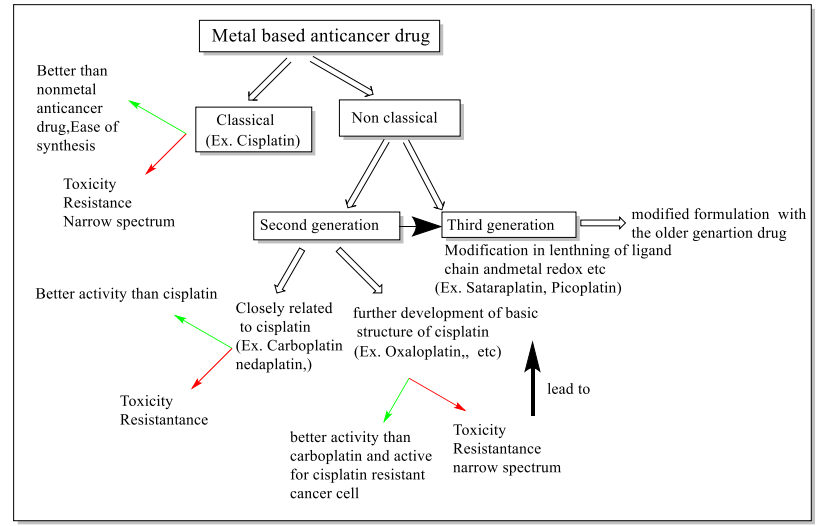

Figure 9- Flow chart of development of platinum based anticancer drug (Green arrow denote advantage and red arrow shows disadvantage) 
Indo Global Journal of Pharmaceutical Sciences, 2018; 8(1): 26-32

ACKNOWLEDGEMENT

Dr. Kanika Bhatt for valuable suggestion on the cancer.

\section{ABBREVIATIONS}

\author{
DNA $=$ Deoxyribonucleic acid \\ $\mathrm{Pd}=$ Palladium \\ $\mathrm{Pt} \quad=$ Platinum \\ $\mathrm{Ru} \quad=$ Ruthenium \\ FDA $=$ Food and Drug Administration \\ $\mathrm{L} \quad=$ Ligand \\ Picoplatin $=$ Cis-amminedichloro, 2-methylpyridine \\ Satraplatin $=$ Bisacetatoammine dichloro \\ cyclohexylamin platinum (IV)
}

\section{REFERENCES}

[1] [a] Rosenberg, Barnett, Loretta Van Camp, and Thomas Krigas. "Inhibition of cell division in Escherichia coli by electrolysis products from a platinum electrode." Nature 205.4972 (1965): 698699. [b] Rosenberg, Barnett, and Loretta Vancamp. "Platinum compounds: a new class of potent antitumour agents." Nature, 222 (1969): 385-386.

[2] [a] Caussanel, Jean-Pierre, et al. "Phase I trial of 5-day continuous venous infusion of oxaliplatin at circadian rhythmmodulated rate compared with constant rate." Journal of the National Cancer Institute 82.12 (1990): 1046-1050. [b] Canetta, R., et al. "Carboplatin: current status and future prospects." Cancer treatment reviews 15 (1988): 17-32.

[3] [a] Siddik ZH. Cisplatin: mode of cytotoxic action and molecular basis of resistance. Oncogene. 2003 Oct 20;22(47):726579. [b] Kelland L. The resurgence of platinum-based cancer chemotherapy. Nature Reviews Cancer. 2007 Aug 1;7(8):573-84. [c] Mistry P, Kelland L. R, Abel, G, Sidhar, S, Harrap, K. R. The relationships between glutathione, glutathione-S-transferese and cytotoxicity of platinum drugs and melphalan in eight human ovarian carcinoma cell lines. Br. J. Cancer 1991, 64, 215-220.

[4] [a] Harrap, K. R. "Preclinical studies identifying carboplatin as a viable cisplatin alternative." Cancer treatment reviews 12 (1985): 21-33. [b] Canetta, Renzo, Marcel Rozencweig, and Stephen K. Carter. "Carboplatin: the clinical spectrum to date." Cancer treatment reviews 12 (1985): 125-136. [c]

Evans, L. M., E. S. Casper, and R. Rosenbluth. "Phase II trial of carboplatin in advanced malignant melanoma." Cancer treatment reports 71.2 (1987): 171-172.[d] Eisenberger M, Hornedo J, Silva H, Donehower R, Spaulding M, Van Echo D. Carboplatin (NSC-241240): an active platinum analog for the treatment of squamous-cell carcinoma of the head and neck. Journal of Clinical Oncology. 1986 Oct 1;4(10):1506-9.

[5] Knox RJ, Friedlos F, Lydall DA, Roberts JJ. Mechanism of cytotoxicity of anticancer platinum drugs: evidence that cisdiamminedichloroplatinum (II) and cis-diammine-(1, 1cyclobutanedicarboxylato) platinum (II) differ only in the kinetics of their interaction with DNA. Cancer research. 1986 Apr 1;46(4 Part 2):1972-9.

[6] Fink D, Aebi S, Howell SB. The role of DNA mismatch repair in drug resistance. Clinical Cancer Research. 1998 Jan $1 ; 4(1): 1-6$.

[7] [a] Farrell NP, De Almeida SG, Skov KA. Bis (platinum) complexes containing two platinum cis-diammine units. Synthesis and initial DNA-binding studies. Journal of the American Chemical Society. 1988 Jul;110(15):5018-9. [b] Farrell N. Nonclassical platinum antitumor agents: perspectives for design and development of new drugs complementary to cisplatin. Cancer investigation. 1993 Jan 1;11(5):578-89.

[8] [a] Graham J, Muhsin M, Kirkpatrick P. Oxaliplatin. Nature Reviews Drug Discovery. 2004 Jan 1;3(1):11-2. [b] Kidani Y, Inagaki K, Iigo M, Hoshi A, Kuretani K. Antitumor activity of 1, 2diaminocyclohexaneplatinum complexes against sarcoma-180 ascites form. Journal of medicinal chemistry. 1978 Dec;21(12):1315-8.[c] Raymond E, Faivre S, Woynarowski JM, Chaney SG. Oxaliplatin: mechanism of action and antineoplastic activity. InSeminars in oncology 1998 Apr (Vol. 25, No. 2 Suppl 5, pp. 4-12) [d] Raymond E, Faivre S, Woynarowski JM, Chaney SG. Oxaliplatin: mechanism of action and antineoplastic activity. InSeminars in oncology 1998 Apr (Vol. 25, No. 2 Suppl 5, pp. 4-12) [e] Bleiberg H. Oxaliplatin (LOHP): a new reality in colorectal cancer. British journal of cancer. 1998 Jun;77(Suppl 4):1.

[9] Raymond E. faivre. S, Chaney, S, Woynarowski, J, Cvitkovik, E. Cellular and molecular pharmacology of oxaliplatin . Mol. Cancer. Ther. 1, 227-235, 2002

[10] Glachetti, S. et al phase III multicenter randomized trial of oxaliplatin added to chromodulated fluorocil-leucovori as first-line treatment of metastatic colorectal cancer J. Cln. Oncol, 2000, 18. 136, 147.

[11] Tan CP, Lu YY, Ji LN, Mao ZW. Metallomics insights into the programmed cell death induced by metal-based anticancer compounds. Metallomics. 2014;6(5):978-95.

[12] [ a]Kelland, Lloyd. "The resurgence of platinum-based cancer chemotherapy." Nature Reviews Cancer 7.8 (2007): 573-584. [b] Justin J. Wilson and Stephen J. Lippard. Synthetic Methods for the Preparation of Platinum Anticancer Complexes. Chem. Rev. 2014, $114,4470-4495$

[13] Ulrike Olszewski, Gerhard Hamilton. A Better platinum based anti cancer drug yet to come? Anti-cancer agents in medicinal chemistry, 2010, 10, 293-301.

[14] [a] Kelland, L.R., Abel, G., McKeage, M.J., Jones, M., Goddard, P.M., Valenti, M., Murrer, B.A. and Harrap, K.R., 1993. Preclinical antitumor evaluation of bis-acetato-ammine-dichlorocyclohexylamine platinum (IV): an orally active platinum drug. Cancer research, 53(11), pp.2581-2586. [b] Kelland, Lloyd R. "An update on satraplatin: the first orally available platinum anticancer drug." Expert Opinion on Investigational Drugs 9.6 (2000): 1373 1382 .

[15] Hartwig JF, Lippard SJ. DNA binding properties of [Pt $(\mathrm{NH} 3)(\mathrm{C} 6 \mathrm{H} 11 \mathrm{NH} 2) \mathrm{Cl} 2]$, a metabolite of an orally active platinum anticancer drug. Journal of the American Chemical Society. 1992 Jul;114(14):5646-54.

[16] Lasorsa A, Stuchlíková O, Brabec V, Natile G, Arnesano F. Activation of Platinum (IV) Prodrugs by Cytochrome $\mathrm{c}$ and Characterization of the Protein Binding Sites. Molecular Pharmaceutics. 2016 Aug 9;13(9):3216-23.

[9f] Sessa C, Minoia C, Ronchi A, Zucchetti M, Bauer J, Borner M, De Jong J, Pagani O, Renard J, Weil C, D'lncalci M. Phase I clinical and pharmacokinetic study of the oral platinum analogue JM216 given daily for 14 days. Annals of Oncology. 1998 Dec 1;9(12):1315-22

[17] Wheate NJ, Walker S, Craig GE, Oun R, The status of platinum anticancer drugs in the clinic and in clinical trials. Dalto trans, 39, 8113- 8127.

[18] Min Y, Li J, Liu F, Yeow EK, Xing B. Near-Infrared Light-Mediated Photoactivation of a Platinum Antitumor Prodrug and Simultaneous Cellular Apoptosis Imaging by Upconversion-Luminescent Nanoparticles. Angewandte Chemie. 2014 Jan 20;126(4):1030-4. 


\section{Indo Global Journal of Pharmaceutical Sciences, 2018; 8(1): 26-32}

[19] Holford J, Raynaud F, Murrer BA, Grimaldi K, Hartley JA, Abrams M, Kelland LR. Chemical, biochemical and pharmacological activity of the novel sterically hindered platinum co-ordination complex, cis-[amminedichloro (2-methylpyridine)] platinum (II)(AMD473). Anti-cancer drug design. 1998 Jan;13(1):1-8.

[20] Holford J, Sharp SY, Murrer BA, Abrams M, Kelland LR. In vitro circumvention of cisplatin resistance by the novel sterically hindered platinum complex AMD473. British journal of cancer. 1998;77(3):366.

[21] [a] Holford J, Sharp SY, Murrer BA, Abrams M, Kelland LR. In vitro circumvention of cisplatin resistance by the novel sterically hindered platinum complex AMD473. British journal of cancer. 1998;77(3):366. [b] Kato T. Phase II study of cis-diammine (glycolato) platinum (254-S), a new platinum complex, for gynecological malignancy. Proc. 16th Int. Congr. Chemother., Anticancer Sect.. 1989;823:1-2.

[c] Abramkin SA, Jungwirth U, Valiahdi SM, Dworak C, Habala L, Meelich K, Berger W, Jakupec MA, Hartinger CG, Nazarov AA, Galanski M. \{(1 R, 2 R, 4 R)-4-Methyl-1, 2 cyclohexanediamine $\}$ oxalatoplatinum (II): a novel enantiomerically pure oxaliplatin derivative showing improved anticancer activity in vivo. Journal of medicinal chemistry. 2010 Oct 1;53(20):7356-64. [d] Jungwirth U, Xanthos DN, Gojo J, Bytzek AK, Körner W, Heffeter $\mathrm{P}$, Abramkin SA, Jakupec MA, Hartinger CG, Windberger U, Galanski M. Anticancer activity of methyl-substituted oxaliplatin analogs. Molecular pharmacology. 2012 May 1;81(5):719-28.

[22] Rogers P, Boxall FE, Allott CP, Stephens TC, Kelland LR. Sequence-dependent synergism between the new generation platinum agent ZD0473 and paclitaxel in cisplatin-sensitive and-resistant human ovarian carcinoma cell lines. European Journal of Cancer. 2002 Aug 31;38(12):1653-60.

[23] [a] Li. H, Gao X, Liu R, Wang, Y, Zhang M, Fu Z, Mi. y, Wang Y, Yao Z, Gao Q. Glucose conjugated platinum (II) complex: antitumor superiority to oxaplatin, combination effect and mechanism of action Eur. J. Med. Chem. 101, 400-408.

[24] Komeda S, Moulaei T, Woods KK, Chikuma M, Farrell NP, Williams LD. A third mode of DNA binding: phosphate clamps by a polynuclear platinum complex. Journal of the American Chemical Society. 2006 Dec 20;128(50):16092-103.

[25] Sood P, Thurmond KB, Jacob JE, Waller LK, Silva GO, Stewart DR, Nowotnik DP. Synthesis and characterization of AP5346, a novel polymer-linked diaminocyclohexyl platinum chemotherapeutic agent. Bioconjugate chemistry. 2006 Sep 20;17(5):1270-9.

[26] P Nowotnik D. AP5346 (ProLindac ${ }^{\text {TM}), ~ A ~ D A C H ~ p l a t i n u m ~}$ polymer conjugate in phase II trials against ovarian cancer. Current Bioactive Compounds. 2011 Mar 1;7(1):21-6.

[27] Stathopoulos GP, Boulikas T, Kourvetaris A, Stathopoulos. J. Liposomal oxaliplatin in the treatment of advanced cancer: a phase I study. Anticancer research. 2006 Mar 1;26(2B):1489-93.

[28] Qian S, Li C, Zuo Z. Pharmacokinetics and disposition of various drug loaded liposomes. Current drug metabolism. 2012 May 1;13(4):372-95.
[29]

[a] Sotiriosrigatos ED, Villiotou V, Stathopoulos JG. Pharmacokinetics and adverse reactions of a new liposomal cisplatin (Lipoplatin): phase I study. Oncology reports. 2005;13:589-95. [b] Koukourakis MI, Giatromanolaki A, Pitiakoudis M, Kouklakis G, Tsoutsou P, Abatzoglou I, Panteliadou M, Sismanidou K, Sivridis E, Boulikas T. Concurrent liposomal cisplatin (Lipoplatin), 5fluorouracil and radiotherapy for the treatment of locally advanced gastric cancer: a phase I/II study. International Journal of Radiation Oncology* Biology* Physics. 2010 Sep 1;78(1):150-5.

[30] Oberoi HS, Nukolova NV, Kabanov AV, Bronich TK. Nanocarriers for delivery of platinum anticancer drugs. Advanced drug delivery reviews. 2013 Nov 30;65(13):1667-85.

[31] Dilruba S, Kalayda GV. Platinum-based drugs: past, present and future. Cancer chemotherapy and pharmacology. 2016 Jun 1;77(6):1103-24.

[31a] To, Kenneth Kin-Wah, Wing-Sum Tong, and Li-wu Fu. "Reversal of platinum drug resistance by the histone deacetylase inhibitor belinostat." Lung Cancer 103 (2017): 58-65.

[31b] Rahman, F.U., Ali, A., Khan, I.U., Duong, H.Q., Yu, S.B., Lin, Y.J., Wang, H., Li, Z.T. and Zhang, D.W., 2017. Morpholine or methylpiperazine and salicylaldimine based heteroleptic square planner platinum (II) complexes: In vitro anticancer study and growth retardation effect on E. coli. European Journal of Medicinal Chemistry.

[32] [a] Allardyce, Claire S., and Paul J. Dyson. "Ruthenium in medicine: current clinical uses and future prospects." Platinum Metals Review 45.2 (2001): 62-69. [b] Alessio E, Mestroni G, Bergamo A, Sava G. Ruthenium antimetastatic agents. Current topics in medicinal chemistry. 2004 Nov 1;4(15):1525-35.

[33] Rademaker-Lakhai JM, van den Bongard D, Pluim D, Beijnen $\mathrm{JH}$, Schellens JH. A phase I and pharmacological study with imidazolium-trans-DMSO-imidazole-tetrachlororuthenate, a novel ruthenium anticancer agent. Clinical Cancer Research. 2004 Jun $1 ; 10(11): 3717-27$

[34] Bloemink MJ, Reedijk J (1996) Cisplatin and derived anticancer drugs: mechanism and current status of DNA binding. Met Ions Biol Syst 32:641-685

[35] Chakravarty J, Bhattacharya S (1996) Ruthenium phenolates. Synthesis, characterization and electron-transfer properties of some salicylaldiminato and 2-(arylazo)phenolato complexes of ruthenium. Polyhedron 15:1047-1055.

[36] [a] Baitalik S, Adhikary B (1997) Heterochelates of ruthenium(II)electrochemistry, absorption spectra, and luminescence properties. Polyhedron 16:4073-4080.[b] Kratz F, Messori L (1993) Spectral characterization of ruthenium(III) transferrin. J Inorg Biochem 49:79-82.

Indo Global Journal of Pharmaceutical Sciences( ISSN 22491023 ; UGC Journal No.: 44477; CODEN- IGJPAI; NLM ID: 101610675) indexed and abstracted in EMBASE(Elsevier), UGC Journal List, National Library of Medicine (NLM) Catalog, Elsevier( EMBASE), ResearchGate, Publons, CAS (ACS), Index Copernicus, Google Scholar and many more. For further details, visit http://iglobaljournal.com 